\title{
TOTAL COLECTOMY AND ILEO-ANAL ANASTOMOSIS IN THE TREATMENT OF ULCERATIVE COLITIS IN CHILDREN*
}

BY

\author{
TYGE CL. GERTZ \\ From the University Clinic of Paediatrics, Copenhagen
}

Modern trends in the treatment of ulcerative colitis are pointing towards earlier and more radical surgery. Ileostomy is no longer found adequate, simultaneous ileostomy and subtotal or total colectomy being the method preferred by most experienced surgeons.

In childhood the disease is relatively rare; in a large series only about one-tenth of all the cases occurred in children (Bargen and Kennedy, 1955). It is, however, apt to take a more serious course. The mortality after medical treatment is high. In a large Swedish series it was $12 \%$ (Lagercrantz, 1955). According to the same series, the chronic, intermittent is the most common type, comprising $79 \%$ of all cases. The disease results in gross delay of growth and maturity and because of long periods of hospitalization the children are unable to follow their normal school education. Cancer is a rare complication in childhood, but cases starting in childhood and persisting 10-20 years are more liable to malignancy than those starting in adulthood. According to Rosenquist, Öhrling, Lagercrantz and Edling (1959), 17 of 26 cases of cancer developed in ulcerative colitis were taken ill with their primary disease before the age of 15 , and cancer may appear even after years of apparent cure. Consequently it must be of current interest to discuss the advisability of early and radical surgical treatment of ulcerative colitis in childhood also.

At the University Clinic of Paediatrics in Copenhagen we have during the last two years performed four colectomies for ulcerative colitis in children, two cases being of the chronic intermittent type and two of the acute, fulminating type. Our first case was interesting in more than one sense.

The patient, a 13-year-old girl, developed ulcerative colitis at the age of 2 years. She had been hospitalized several times during infancy, and was treated medically according to the current methods until the age of 11

\footnotetext{
* A paper read at a meeting of the British Association of Paediatric Surgeons held in Liverpool in June, 1959.
}

when an ileostomy was performed. This operation had a very good effect upon her general condition although the inflammatory changes persisted. One and a half years later a subtotal colectomy was performed. The colon was grossly inflamed with large ulcerations and pseudopolyposis and in two different areas in the transverse colon cancer had developed (Fig. 1). The

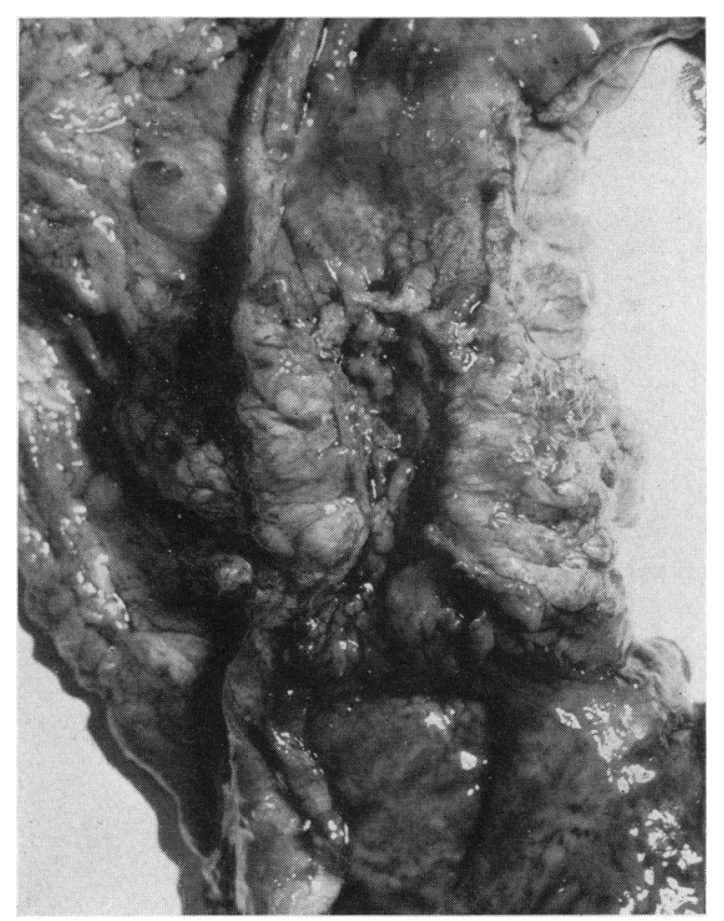

Fig. 1.

rectum was not removed. The operation was thought to be radical and the post-operative course was smooth.

Two months afterwards an ileo-rectal end-to-side anastomosis was done. On this occasion no signs of recurrence of the cancer were found, but three months 
later she was readmitted acutely ill with symptoms of ileus. At laparotomy it was found that she had a diffuse peritoneal carcinosis. Of course nothing could be done and the child succumbed to her disease in a month. At autopsy it was found that a severe ulcerative proctitis had recurred.

From this case we learned firstly that cancer may very well develop in spite of an ileostomy, showing the importance of a total or subtotal colectomy, once surgical treatment has been decided upon. Secondly we learned that ileo-rectal anastomosis is not the ideal procedure since it may be followed by recurrence of a haemorrhagic proctitis.

Ileo-rectal anastomosis has been advocated for selected cases by several authors (Corbett, 1958; and Aylett,1957, in England) and has also been used in children (Ehrenpreis, 1959). We feel, however, that owing to the risk of relapse of ulcerative proctitis in the remaining part of the rectum and also to the risk of cancer, total colectomy must be the preferred procedure. Since a permanent ileostomy, even with modern equipment, is very incapacitating, especially in a child or a young person, we decided to attempt an ileo-anal anastomosis.

Up till now we have done this operation in two cases. They have both been operated on in two stages, the first stage being ileostomy and subtotal colectomy. Six months later we anastomosed the ileum to the anus and removed the rectum using the pull-through technique described by Swenson (1958) for Hirschsprung's disease. We have found it important to postpone the second stage at least six months. In the intervening period the general health can be re-established and the blood chemistry, which may be difficult to keep within normal ranges during the first period after ileostomy, can be regulated. Also in the span of six months the stools will become semi-solid, owing to an increasing absorption of liquid from the terminal ileum, and are thus less irritating.

From a technical point of view the second stage has been easy, the only difficulty being the isolation of the rectum down to the anus. Because of inflammation it was in both cases very adherent to the surrounding structures. The removed rectum was in both cases grossly inflamed except for the most distal part.

Our first patient thus treated was a 13-year-old girl. Her illness started at the age of 5 years and was of the chronic, intermittent type. The final operation, an ileoanal anastomosis, was performed a year ago. She is now in excellent health. She has four to five bowel movements during the day, the stools being semi-solid and not irritating, and she is completely continent and undisturbed during her sleep. She now attends school without absence.
Our second case was a 7-year-old boy with an acute fulminating ulcerative colitis. The ileo-anal anastomosis was performed a couple of months ago. With the exception of some incontinence his convalescence was uneventful. On discharge, which took place only recently, he was in excellent health with a promising weight curve.

A third case, a 13-year-old boy, also suffered from the acute fulminating type and had a colectomy six months ago (Fig. 2). He still has his ileostomy and is in very good

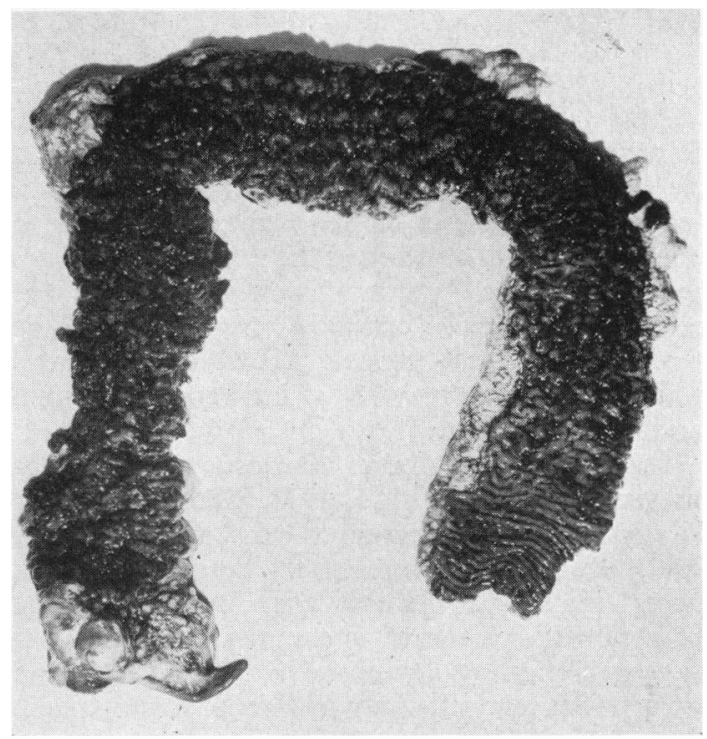

FIG. 2.

condition. It is our intention to perform an ileo-anal anastomosis this autumn.

\section{Summary}

In children ulcerative colitis is apt to take a rather fulminant course. Medical treatment is tedious and takes a very long time. In our experience children will stand a radical colectomy and ileostomy very well and will develop in a natural way afterwards. It has, however, been our aim to avoid an incapacitating permanent ileostomy. An ileo-anal anastomosis, using the same technique as in Swenson's pull-through operation for Hirschsprung's disease, has up till now been used in two cases and seems to be a promising solution.

\section{REFERENCES}

Aylett, Stanley (1957). Brit. med. J., 1, 489.

Bargen, J. A. and Kennedy, R. L. J. (1955). Postgrad. Med., 17, 127. Corbett, Rupert S. (1958). Amer. J. Surg., 96, 684.

Corbett, Rupert S. (1958). Amer. J. Surg.,

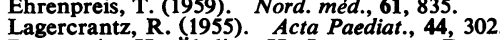

Rosenquist, H., Öhrling, H., Lagercrantz, R. and Edling, N. (1959). Lancet, 906.

Swenson, O. (1958). Pediatric Surgery. Appleton-Century-Crofts, New York 